\title{
Chemistry and Applications of Phosphorylated Chitin and Chitosan
}

\author{
R. Jayakumar, ${ }^{1,2^{*}}$ R. L. Reis, ${ }^{1,2}$ J. F. Mano ${ }^{1,2}$ \\ 13B's Research Group-Biomaterials, Biodegradables and Biomimetics, University \\ of Minho, Campus of Gualtar, 4710-057 Braga, Portugal \\ ${ }^{2}$ Department of Polymer Engineering, University of Minho, Campus of Azurem, \\ 4800-058 Guimaraes, Portugal. Fax; +351 253510330; E-mail; jayakumar77 \\ @yahoo.com
}

(Received: 18 May, 2006; published: 7 July, 2006)

\begin{abstract}
Chitin and chitosan are natural based non-toxic, biodegradable and biocompatible polymers and have been used in biomedical areas in the form of sutures, wound healing materials and artificial skin, and for the sustained release of drugs as well as in various industrial applications. However, practical use of these polymers has been mainly confined to the unmodified forms. Recently, there has been a growing interest in chemical modification of chitin and chitosan to improve their solubility and widen their applications. Among them, phosphorylated chitin and chitosan have attracted considerable interest because of their various advantages: anti-inflammatory property, ability to form metal complexes, blood compatibility and formation of anionic polyelectrolyte hydrogels. The purpose of this review is to take a closer look of different synthetic methods of phosphorylated chitin and chitosan and their potential applications in environmental, food, fuel cell, and biomedical fields. Based on current research and existing products, some new and futuristic approaches in this context area are discussed.
\end{abstract}

\section{Introduction}

Chitin, a naturally abundant mucopolysaccharide, and the supporting material of invertebrates such as crustaceans, insects, consist of a homopolymer of $\beta(1 \rightarrow$ 4) linked 2-acetamido-2-deoxy- $\beta$-D-glucose residues. Its immunogenicity is exceptionally low, in spite of the presence of nitrogen. It is a highly insoluble material resembling cellulose in its solubility and chemical reactivity. Chitosan is the $\mathrm{N}$-acetylated derivative of chitin, although this $\mathrm{N}$-deacetylation is almost never complete [1,2]. Chitin and chitosan are of commercial interest due to their high percentage of nitrogen $(6.89 \%)$ compared to synthetically substituted cellulose $(1.25 \%)$. As most of the present-day polymers are synthetic materials, their biocompatibility and biodegradability are much more limited than those of natural polymers such as cellulose, chitin, chitosan and their derivatives. However, these naturally abundant materials also exhibit a limitation in their reactivity and processability $[3,4]$. In this respect, chitin and chitosan are recommended as suitable functional materials, because these natural polymers 
have excellent properties such as biocompatibility, biodegradability, non-toxicity and adsorption properties [5-7].

Chitin and chitosan derivatives are used in various fields [8,9] treating water [1011], biomedical [12-19], cosmetic [19, 20], agricultural [21] or food industrial [22, 23]. It shows some biological activities such as immunological [24], antibacterial [25], wound healing activity [26], drug delivery [27-30] and has been proposed for tissue engineering applications [31-33]. Chemical modification of chitin and chitosan to generate new biofunctional materials is of primary interest because such procedure would not change the fundamental skeleton of chitin and chitosan and would keep the original physicochemical and biochemical properties depending on the nature of the group introduced $[7,20,26]$. Introduction of groups such as phosphonic acid or phosphonate onto chitin and chitosan by reaction of phosphorylating agent onto the amino groups are known to increase the chelating properties [34-36] of chitin and chitosan and could modify its solubility. Several techniques to obtain phosphate derivatives of chitin and chitosan have been proposed due to the interesting biological and chemical properties of such compounds.

A few review articles on the potential applications of chitin and chitosan for pharmaceutical, veterinary medicine, biomedical and environmental field have already been reported $[10,20,23,25,37-42]$. However, there is no comprehensive review about phosphorylated chitin and chitosan and its synthesis method and applications. This review intends to systematize related issues that include the various methods of preparation of phosphorylated chitin and chitosan. Moreover, the potential applications of phosphorylated chitin and chitosan in fields such as adsorbing metal ions, drug delivery, fuel cells, blood compatibility, food and tissue engineering are also discussed. The present review is an attempt to discuss the current applications and future prospects on the use of phosphorylated chitin and chitosan.

\section{Synthesis of phosphorylated chitin and chitosan}

The poor solubility of chitin and its derivatives in common solvents has been a major drawback to its utilization. Chemically modified chitin derivatives have good solubility in many solvents promoting the usefulness of this polysaccharide resource. Many efforts have been reported to prepare functional derivatives of chitin and chitosan by chemical modifications, in order to increase the solubility in water [43-47]. The reaction of chitin with phosphorous pentoxide was found to give water soluble phosphorylated chitin of high degree of substitution (DS). Phosphorylated chitin (P-chitin) and chitosan (P-chitosan) were prepared by heating chitin or chitosan with orthophosphoric acid and urea in DMF $[48,49,50]$ (Fig. 1).

P-chitin and P-chitosan were also prepared by the reaction of chitin or chitosan with phosphorous pentoxide in methanesulphonic acid [51, 52]. The phosphorylation reactions of chitin and chitosan in phosphorous pentoxidemethane sulphonic acid were found to be a very efficient reaction [53-56]. Methanesulphonic acid worked as an efficient catalyst for the esterification 
reaction. It was reported that DS of the products increased with increasing amount of phosphorous pentoxide, and the products became nearly fully phosphorylated with $4.0 \mathrm{~mol}$.

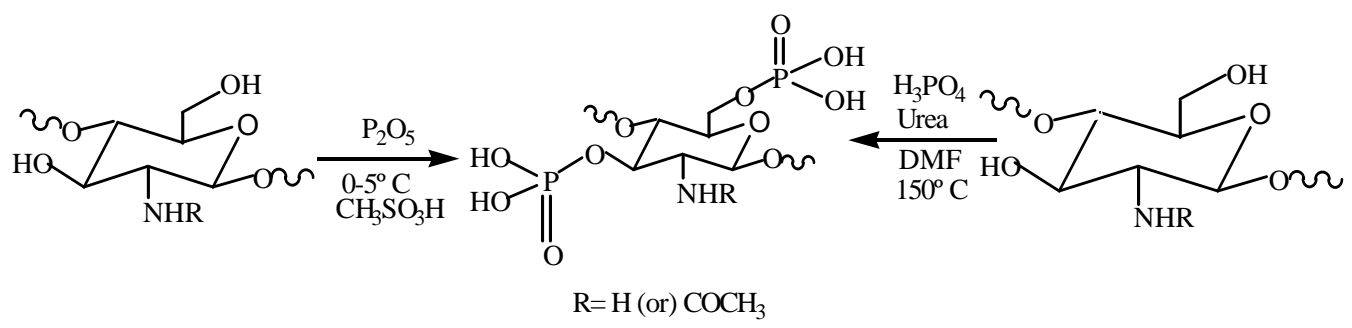

Fig. 1. Synthesis of phosphorylated chitin and chitosan.

However P-chitosan of high DS was insoluble in water while those of low DS were soluble. The insoluble character of P-chitosan of high DS may be attributed to the formation of inter- or intramolecular salt linkage between amino and phosphate groups due to the formation of poly-ion complex as generally seen in polyampholities. Nishi and co-workers [57] prepared P-chitin and P-chitosan by the cross-linking reaction with adipoyl chloride in methanesulphonic acid with phosphorous pentoxide for adsorbing metal ions. The cross-linking reaction was carried out with adipoyl chloride immediately after the reaction with phosphorous pentoxide without isolating $\mathrm{P}$-chitin or $\mathrm{P}$-chitosan. These products were completely insoluble in water, and were proposed to be used as adsorbents of metal ions in water.

The synthesis of anionic, heteroatom containing carbohydrate polymers are of interest for a variety of reasons including the preparation of anticoagulants, metal-chelating agents, and fire-retardant materials. For these and other commercial uses, inexpensive methods are desirable to facilitate the incorporation of phosphorous containing residues into polysaccharides. The Pchitin and P-chitosan were synthesized by mixing chitin or chitosan with sodium pyrophosphate [58]. P-chitosan was also synthesized by grafting mono(2methacryloyl oxyethyl)acid phosphate onto chitosan [59]. It was observed that the grafting reaction improved the antimicrobial activities of chitosan. It was also observed that the antimicrobial activity of chitosan and graft copolymer against Candida albicans, Trichophyton rubrum, and Trichophyton violaceum depends largely on the amount and type of grafted chains, as well as on the changes of $\mathrm{pH}$ [59].

The incorporation of methylene phosphonic groups into chitosan allowed solubility in water under neutral conditions without decreasing its filmogenic properties [60]. A water soluble $\mathrm{N}$-methylene phosphonic chitosan (NMPC) was synthesized using chitosan, phosphorous acid and formaldehyde [60] (Fig. 2). The introduction of the phosphonic acid function in the chitosan macromolecule via the Moedritzer and Irani [61] reaction is modified with phosphoric acid and formaldehyde yielding a chitosan derivative with different properties from chitosan. The viscosity of NMPC was practically independent $\mathrm{opH}$, and these 
solutions at $\mathrm{pH} 6.8$ became insoluble and precipitated as a white product. NMPC was prepared from chitosan with different acetylation degrees and time interval [62]. A significant decrease of viscosity and molecular weight was observed due to derivatization. The viscosity studies showed that, for 20 and $30 \mathrm{~h}$ reaction times a considerable decrease was observed. As a consequence of the phosphonomethylation, the crystallinity of the polymer was decreased drastically.

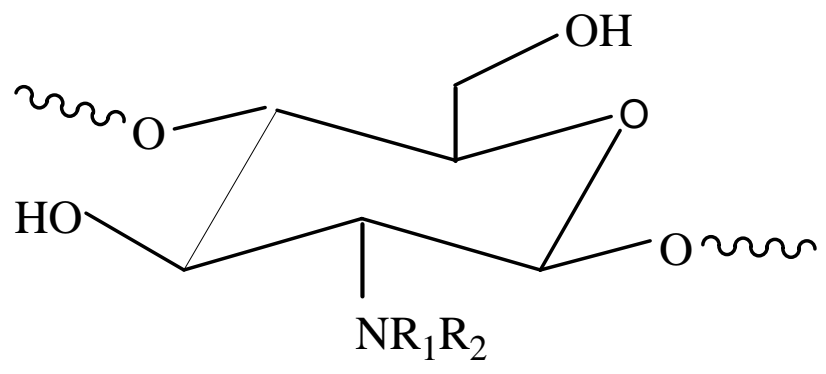

$$
\begin{aligned}
& \mathrm{R}_{1}=\mathrm{H}, \mathrm{R}_{2}=\mathrm{CH}_{2} \mathrm{PO}_{3} \mathrm{H}_{2} \\
& \mathrm{R}_{1}=\mathrm{R}_{2}=\mathrm{CH}_{2}-\mathrm{PO}_{3} \mathrm{H}_{2}
\end{aligned}
$$

Fig. 2. Chemical structure of $\mathrm{N}$-methylene phosphonic chitosan.

$$
[-\mathrm{A}-/-\mathrm{B}-/-\mathrm{C}-/-\mathrm{D}-/-\mathrm{E}-/ \ldots] \mathrm{n}
$$

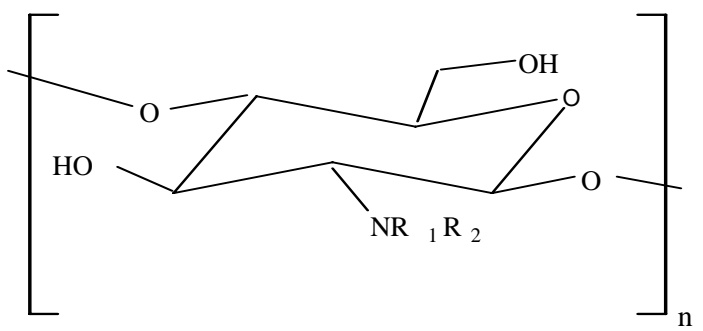

\begin{tabular}{|l|l|l|}
\hline & $\mathrm{R}_{1}$ & $\mathrm{R}_{2}$ \\
\hline$A$ & $-\mathrm{H}$ & $-\mathrm{CO}-\mathrm{CH}_{3}$ \\
\hline$B$ & $-\mathrm{H}$ & $-\mathrm{H}$ \\
\hline$C$ & $-\mathrm{H}$ & $-\mathrm{CH}_{2}-\mathrm{PO}_{3} \mathrm{H}_{2}$ \\
\hline$D$ & $-\mathrm{CH}_{2}-\mathrm{PO}_{3} \mathrm{H}_{2}$ & $-\mathrm{CH}_{2}-\mathrm{PO}_{3} \mathrm{H}_{2}$ \\
\hline$E$ & $-\mathrm{H}$ & $-\left(\mathrm{CH}_{2}\right)_{11}-\mathrm{CH}_{3}$ \\
\hline
\end{tabular}

Fig. 3. Chemical structure of $N$-lauryl- $N$-methylene phosphonic chitosan (LMPC).

$N$-lauryl carboxymethyl chitosan with both hydrophobic and hydrophilic groups was studied [63] in connection with delivery of taxol to cancerous tissues. Other examples are related to the production of polymeric vesicles for encapsulation of hydrophobic compounds like bleomycin [64]. NMPC offer the presence of 
hydrophobic and hydrophilic branched for controlling solubility properties and leads to a new chitosan derivative surfactant. A simple methodology for the preparation of new chitosan derivative surfactant, $N$-lauryl- $N$-methylene phosphonic chitosan (LMPC), has been developed and reported [65] (Fig. 3). LMPC incorporated $\mathrm{N}$-methylene phosphonic groups as hydrophilic moieties and lauryl groups as hydrophobic one. Therefore, LMPC derivatives open new perspectives in the pharmaceutical and the cosmetic fields.

$\mathrm{N}$-Phophonomethylation of chitosan reaction was studied and optimized using different reaction conditions [66]. The reaction was conducted with a large excess of both phosphorous acid and formaldehyde at $70^{\circ} \mathrm{C}$. The obtained white solid is soluble in water and acidic solution. The NMR analysis showed that the side product is formed during the phosphonomethylation reaction of chitosan. The mechanism was proposed for its formation, based on the Leuckart-Wallach reaction [67-69]. The carboxymethylation of NMPC consisted in reacting with the free amino groups to yield a novel polyfunctional amine derivative. The multidendate soluble derivative has potential chelating ability not only for transitions metal ions but also for calcium ions [45, 35, 70-72].

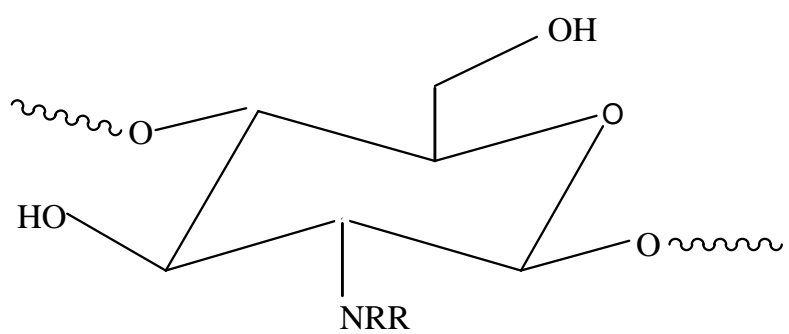

Where $\mathrm{R}=\mathrm{CH}_{2}-\mathrm{PO}_{3} \mathrm{H}_{2} \quad \& \quad \mathrm{R}=\mathrm{CH}_{2} \mathrm{COOH}$

Fig. 4. Chemical structure of $\mathrm{N}$-methylene phosphonic $\mathrm{N}$-methylene carboxylic chitosan (NMPCC).

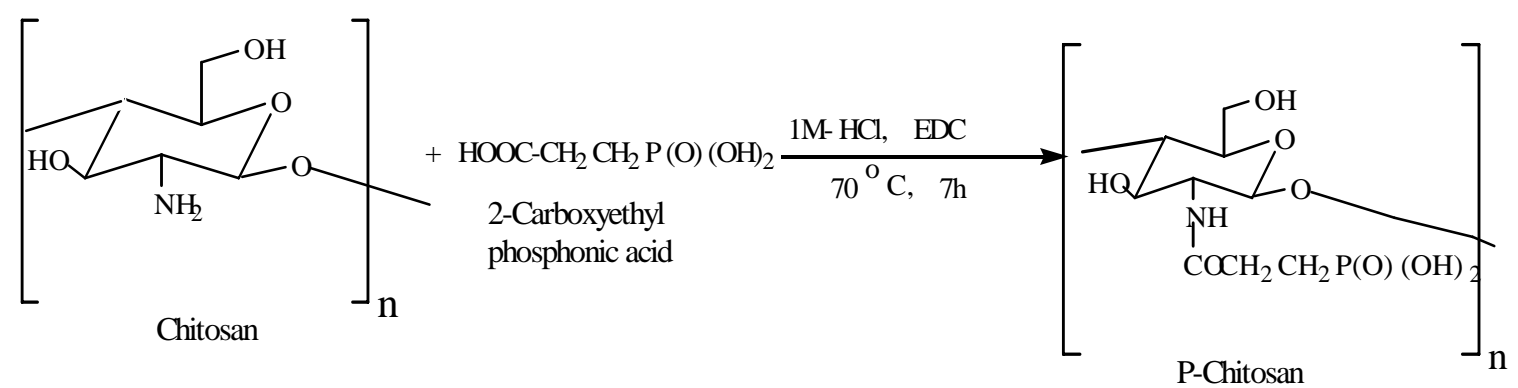

Fig. 5. Synthesis of P-chitosan by grafting method.

Ramos and co-workers [73] prepared $N$-methylene phosphonic and carboxylic chitosan (NMPCC) by using NMPC and glyoxallic acid (via aldimine formation) under reduction conditions with sodium borohydride. This new chitosan 
multidentate ligand is carrying both carboxylic and phosphonic groups [73] (Fig. 4). The films obtained from NMPCC were translucent, brilliant and mechanically resistant and had homogeneous appearance. The XRD studies showed NMPCC was amorphous in nature and also soluble in water. The crystallinity of Chitosan was decreased due to the phosphorylation. P-Chitosan was also synthesized by means of graft copolymerization [74]. 2-Carboxethylphosphonic acid was covalently grafted onto chitosan by using 1-ethyl-3-(3-dimethylaminopropyl) carbodiimide (EDC) mediated coupling reaction (Fig. 5).

\section{Applications of $P$ - chitin and P-chitosan}

\section{-Adsorbing metal ions}

The P-chitin and P-chitosan are found to be a strong metal-binding ability. It was found that their adsorption of uranium is much greater than of the other heavy metal ions [50, 75, 76]. P-chitin and P-chitosan were cross-linked with adipoyl chloride in methanesulphonic acid, and their metal binding ability to $\mathrm{Mg}^{2+}, \mathrm{Ca}^{2+}$, $\mathrm{Sr}^{2+}, \mathrm{Ba}^{2+}, \mathrm{Mn}^{2+}, \mathrm{Ni}^{2+}, \mathrm{Cu}^{2+}, \mathrm{Zn}^{2+}$ and $\mathrm{Cd}^{2+}$ was reported [57]. Conversion of chitin to insoluble $\mathrm{P}$-chitin resulted in the increase of the binding ability to all metal ions and this was tested. The results indicated that the alkaline earth metals and $\mathrm{Mn}^{2+}$ were adsorbed strongly to these derivatives than to chitin or chitosan [57]. However, it was also found that the transition elements except $\mathrm{Mn}^{2+}$ were adsorbed strongly to chitosan than to these derivatives in their experimental condition. For the binding of $\mathrm{Mg}^{2+}, \mathrm{Ca}^{2+}, \mathrm{Sr}^{2+}, \mathrm{Ba}^{2+}$ and $\mathrm{Mn}^{2+}$, in which insoluble $\mathrm{P}$-chitin or insoluble P-chitosan were superior in their metal-binding ability to chitin or chitosan, insoluble P-chitosan I (45\% deacetylated) showed higher performanace than both insoluble P-chitin (less than 5\% deacetylated) and insoluble P-chitosan II (97\% deacetylated). These results indicated that halfdeacetylated derivatives among chitosan and P-chitosan present the highest metal-binding ability [57]. $\mathrm{Ca}^{2+}$ binding ability of insoluble P-chitin and P-chitosan were far larger than their starting materials in a wide $\mathrm{pH}$ range [57]. This would suggest the large contribution of the phosphoryl group to the $\mathrm{Ca}^{2+}$ binding. It also indicates that insoluble P-chitosan I show the highest binding ability in the studied $\mathrm{pH}$. From these results, we concluded that the binding ability to alkaline earth metals was significantly enhanced by the introduction of phosphate group.

Schwarzenbach et al [36] considered that the phosphonic complexing agents were as effective or even more than those containing carboxylic groups. The aminoalkylphosphonic ligands $\left(\mathrm{NH}_{2}-\mathrm{CH}_{2}-\mathrm{PO}_{3}{ }^{2-}\right)$ have well known strong chelating properties owing to the donor effect of the amine group $\left(-\mathrm{NH}_{2}\right)$ and the monodentate ligand as $-\mathrm{PO}_{3}{ }^{2-}$ [34]. They have tendency to form chelates in ring structure with possibilities of different conformations owing to the metal ion nature. In the case of NMPC $\left(\mathrm{NH}_{2}-\mathrm{CH}_{2}-\mathrm{PO}_{3}{ }^{2-}\right)$ the presence of an amine group from chitosan combines these two effects, increasing the metal binding abilities [35]. One of the properties of NMPC is its ability to chelate not only transitionmetal ions, but also calcium ions [62]. From their results, the NMPC was a powerful chelating agent of transition metal and calcium ions. 


\section{Fuel cell applications}

The conductance measurements in P-chitosan were analyzed and reported [77]. P-chitosan membranes were almost non conductive in their dry states and hydrated membranes showed ionic conductive properties that can be one order of magnitude higher than unmodified chitosan membranes. Although crystallinity of P-chitosan membranes and the corresponding swelling index had changed pronouncedly, these membranes did not significantly lose their strength and thermal stability in comparison with unmodified chitosan membranes. From these results, P-chitosan membranes could have potential to be applied in alkaline polymer electrolyte fuel cells in the future. Yamada and Honma prepared an anhydrous proton-conducting membrane using a composite of P-chitin and the basic heterocycle imidazole $(\mathrm{Im})$ [78]. A composite material of P-chitin and 200 wt $\%$ Im showed a high proton conductivity of $7 \times 10^{-3} \mathrm{Scm}^{-1}$ at $150{ }^{\circ} \mathrm{C}$ under anhydrous (water free) conditions. Additionally, the thermal stability of P-chitin/Im composite material was increased with the doping ratio of the imidazole. The utilization of a biopolymer such as P-chitin for polymer electrolyte membrane fuel cells technologies is novel, challenging, inexpensive, and environmentally benign. Application of these biopolymers in electrical devices would be attractive not only in the terms of product cost and environmental safety but also from a material science point of view.

\section{Drug delivery applications}

Chitosan based materials has been used in systems for the sustained release of drugs [23, 79, 80-84]. P-chitosan was used for the preparation of gel beads using TPP to improve the controlled release system in a gastrointestinal fluid [85]. This work included the in vitro drug release profiles monitored at various $\mathrm{pH}$ media at $37^{\circ} \mathrm{C}$ using ibuprofen (lb) as a model drug. The release percents of ibuprofen from $\mathrm{P}$-chitosan gel beads were found to increase with increasing $\mathrm{pH}$ of the dissolution medium. This behavior indicated that the drug release profile is $\mathrm{pH}$ sensitive. The release rate of ibuprofen at $\mathrm{pH} 7.4$ was noticeably higher than the release rate at $\mathrm{pH} 1.4$ due to the ionization of phosphorous groups and high solubility of ibuprofen at $\mathrm{pH} 7.4[86,87]$ and also the electrostatic repulsion between negatively ionized carboxyl groups of $\mathrm{lb}$ and phosphate groups in Pchitosan molecules. The release rate in simulated intestinal fluid $(\mathrm{pH} 7.4)$ was higher than that in simulated gastric fluid $(\mathrm{pH} 1.4)$, enabling the drug delivery or release to take place preferentially in the intestine with avoiding simultaneously the drug leakage in the stomach. All of these interesting features indicated that the PCS gel beads could be used as successful drug carrier for controlled drug delivery in oral administration.

Win and co-workers investigated the effect of proteolytic enzymes on the in vitro release of $\mathrm{Ib}$ from P-chitosan in microspheres in simulated gastric fluid (SGF) (pH 1.4) and simulated intestinal fluid (SIF) (pH 7.4) [88]. To reduce the enzymatic degradability and to enhance the sustained release property, polyelectrolyte complex microspheres based on P-chitosan by using TPP were developed and characterized. The $\mathrm{lb}$ released from $\mathrm{P}$-chitosan microspheres sustained more 
effectively than that from CS microspheres in the medium of proteolytic enzymes such as pepsin and trypsin, respectively. These P-chitosan microspheres could serve as a good candidate for oral drug-delivery systems with sustained release properties due to their higher stability in SGF and SIF containing hydrolytic enzymes. Similarly, P-Chitosan beads were also synthesized by using TPP with indomethacin drug and the in vitro drug releases were carried out at different $\mathrm{pHs}$ [74]. The release rate of indomethacin at $\mathrm{pH} 7.4$ was higher than that at $\mathrm{pH} 1.4$, due to the ionization of phosphorous groups and high solubility of indomethacin in the alkaline medium. These results indicated that PCTS beads have potential to be used as controlled drug delivery systems through oral administration since the drug release in the highly acidic gastric fluid region of the stomach is avoided.

\section{Food applications}

NMPC and LMPC are being studied as a result of their broad range of food applications. These biopolymers offer a wide range of unique applications including formation of biodegradable films, immobilization of enzymes, preservation of food from microbial deterioration, as additives (clarification and deacidification of fruits and beverages, emulsifying agents, thickening and stabilizing agents, color stabilization), and dietary supplements. The introduction of phosphonic groups into chitosan provided water solubility and potential chelating and emulsifying abilities in food applications [62].

\section{Tissue engineering and other biomedical applications}

Tissue engineering has emerged as a new area of regenerative medicine, with the capability of surpassing some of the disadvantage of using pure synthetic materials, in conventional replacement procedures. The common concepts associated in the tissue engineering research are based on the construction of hybrid materials obtained from the incorporation of cells (and other biological agents such as growth factors) into a 3D porous scaffold or hydrogel. The scaffold material has an essential function concerning cell anchorage, proliferation and tissue formation in three dimensions. The material should be able to process into porous scaffold structures, with the porosity characteristics being application specific. Recently, chitosan and its derivatives have been reported as attractive candidates for scaffolding materials because it is expected that they degrade as the new tissues is being formed, eventually without inflammatory reactions or toxic degradation $[25,89,90]$.

Calcium-phosphate based-bioceramics, in the form of powder, granules and coatings are currently used in for a number of dental and skeletal prosthetic applications by virtue of their excellent biocompatibility and osteointegration process [91]. Recently, calcium phosphate materials are being grown biomimetically over different surface-modified substrates in order to gain insight into how to develop biomaterials with tailored surface properties that can initiate calcium phosphate deposition when implanted at bony sites [92-94]. The nucleation or precipitation of hydroxyapatite over different material surfaces can be achieved by either (a) raising the ionic activity product of calcium phosphate in 
the solution, thereby stimulating precipitation and creation of apatite nucleation sites [95] or by a (b) surface functionalization method, used to create favorable local conditions that lead to the nucleation and growth of calcium phosphate [9698]. These techniques are mainly based on functionalization and subsequent immersion of the substrate material in simulated body fluid solution (SBF). Phosphate group as functionalization radical was found to be very effective for the deposition of hydroxyapatite over cotton, chitin [97, 98]. Prior to immersion in $\mathrm{SBF}$, the phosphorylated substrate is subjected to soaking in saturated $\mathrm{Ca}(\mathrm{OH})_{2}$ solution. This treatment creates a number of calcium precursor sites over the surface that will eventually create favorable condition for the nucleation and growth of HAP.

Calcium phosphate growth on P-chitin fibers and P-chitosan films were studied $[98,99]$. Chitin fibres of P-Chitosan films were soaked in saturated $\mathrm{Ca}(\mathrm{OH})_{2}$ solution at ambient temperature. It is believed that the thin coatings of calcium phosphate material on the fibers produced by partial hydrolysis of the chitin $\mathrm{PO}_{4}$ functionalities during soaking in saturated $\mathrm{Ca}(\mathrm{OH})_{2}$ solution acted as a nucleation layer upon which the calcium phosphate can grow from the SBF solution. In general, the growth of calcium phosphate from SBF begins immediately after 1 day of soaking. This suggested that clusters have partially dissolved upon introduction of the chitin and chitosan into the SBF solution. The growth of calcium phosphate layer after soaking for 1-6 days appears to proceed by nucleation on the existing coating in the form of circular flakes, which then grow in number and size on the surface. After soaking for 9-17 days, the thicker coating was observed. The P-chitin fiber and P-chitosan films which were not subjected to the $\mathrm{Ca}(\mathrm{OH})_{2}$ treatment did not exhibit calcium phosphate growth upon immersion in SBF. During the $\mathrm{Ca}(\mathrm{OH})_{2}$ treatment, a calcium phosphate precursor phase is expected to be formed all over the chitosan surface which will initiate calcium-deficient HAP growth on subsequent immersion in SBF solution.

Chitin/chitosan-calcium phosphate systems have potential to be used as virus filters, given the adsorptive properties of hydroxyapatite [100-101] which may allow the attachment of drugs for treatment of viral diseases. The biocompatibility of the samples was evaluated by cell culture test using L-929 cells and better results were obtained in the coated sheets. Recent approaches towards the development of chitin as a hard tissue substitute material take into consideration the interaction of chitin with calcium phosphate. Cumulative research in the field of bone repair has introduced concepts, which relate the bioactivity of a material to its calcification properties [102]. Surfaces, which can induce the formation of an apatite layer in vitro, or if it is coated with an apatite layer, may demonstrate, improved bone-binding properties [103]. A material with the propensity to clarify in vivo also encourages post-operative formation of calcium phosphate phases [104]. In addition, favorable interactions between the implant material and calcium phosphate will also ensure in vivo stability of the particular calcium phosphate coating [105]. Extensive studies investigating the influence of various factors on the crystallization of calcium phosphate have been performed since the 1950s. Most of these studies were focused towards uncovering the role of various acidic proteins of the human bone matrix $[106,107]$. Many of the factors 
in the soluble state displayed an inhibitory effect towards calcium phosphate formation while others promoted mineralization [108-111]. The potential of chitinbased materials as a bone substitute material for orthopedic applications warrants the need to study the influence of their acidic derivatives on both heterogeneous and homogeneous calcium phosphate precipitation and crystallization [112].

The influence of two-water soluble anionic derivatives, sodium carboxymethylchitin (CM-chitin) and P-chitin on the crystallization of calcium phosphate by seeded growth and turbidity were studied [113]. The results showed that the CMchitin exerted only a slight but noticeable effect on hydroxyapatite seeded growth. In contrast, P-chitin appears to demonstrate a very potent inhibitory effect. The behavior of P-chitin is similar to phosphoserine and phosphatidylserine where pronounced inhibitory effects on hydroxyapatite seeded growth were found $[114,115]$. Macroporous scaffolds were obtained through a freeze-drying technique using both NMPC and CS [116]. Biomimetic mineralization was carried out in different media, i.e., SBF or $\mathrm{CaCl}_{2}$ and $\mathrm{Na}_{2} \mathrm{HPO}_{4}$ solutions [116]. NMPC with phosphonic groups led to clear differences in the ability of scaffold wall surface to support heterogeneous calcium phosphate nucleation and growth. CS scaffold incubated in SBF for 20 days did not display mineral growth, whereas NMPC scaffold showed increasing mineral particulates, surface coverage with an essential continuous mineral layer. The biomineralization behavior of NMPC was superior to that of CS at higher soaking cycle number. Moreover, these scaffolds only deposit apatite slightly in SBF. This result provided NMPC derivatives constituting biocomposite scaffold with improved compressive stiffness. Similarly, it has been reported calcium phosphate mineral was formed on P-chitosan membranes after soaking with $\mathrm{Ca}(\mathrm{OH})_{2}[117]$.

Large bone and skeletal repair are always a tough problem of surgeons in clinics. The natural biological materials for bone defect repair, including autografts and allografts, each has its own shortcomings such as donor site morbidity and donar shortage for autografts [118], immunologic response and endothermic risk for allografts [119]. Although numerous synthetic bone substitutes using metals, ceramics, and polymers have been developed to promote bone regeneration for several decades, there exists a lack of confidence in their biological performances, particularly in view of long term, in vivo safety and efficiency [120]. For example, metals are difficult to shape and have a problem of corrosion, which leads to inflammatory responses of surrounding tissue [121, 122]. Polymers are usually encapsulated and do not integrate with tissue, resulting in implant movement, inflammatory responses, and implant extrusion [121, 123]. Ceramics are fragile and difficult to sculpt to skeletal defects [120,124, 125].

Recently, much attention has been paid to calcium phosphate cements (CPCs), for their highly osteoconductivity, readily osteointegrated, easily shaped (injected) and gradually degradable properties $[126,127]$. However, when compared with natural bone, the lack of toughness and binding ability are still their undesired properties. So, some researchers added water-soluble polymers such as sodium 
aliginate [128], hydroxypropyl methylcellulose and carboxymethylcellulose [129] into tetracalcium phosphate (TTCP) containing cements to improve the handling properties. The water-soluble P-chitosans that could be quickly biodegraded by lysozyme in vivo was prepared and mixed with two easily prepared CPCs [130, 131]. Monocalcium phosphate monohydrate (MPCM) with calcium oxide $(\mathrm{CaO})$ in $1 \mathrm{M}$ phosphate buffer (CPC-I) and dicalcium phosphate dehydrate (DCPD) with calcium hydroxide $\left[\mathrm{Ca}(\mathrm{OH})_{2}\right]$ in $1 \mathrm{M} \mathrm{Na}_{2} \mathrm{HPO}_{4}$ solution (CPC-II). With certain amount of P-chitosan, the resulted P-chitosan containing CPCs (P-CPCs) have high mechanical strength and slightly prolonged setting time. In vitro experiments have shown that P-chitosan can increase the dissolubility of the start materials of cements and bind calcium phosphate strongly afterwards [132]. Since slight difference in CPC compositions may lead a considerable change of clinical result, further animal tests of the CPC and P-CPCs in radial and tibial defects of rabbits were performed [132]. The biocompatible, bioabsorabable and osteoinductive properties were evaluated. No osteolysis, hyperplasia or other negative responses were found in the CPC and P-CPC containing samples through the study of 22 weeks. Histological examination has also revealed that bone repair in the P-CPCs showed full different manner with CPC, in which microphages appeared around implants. The biodegradation rate of the implants was found to depend on the P-chitosan content: and the samples with more content of P-chitosan showed the slower degradation rate. Thus, for the rapid repair of no loading bone, the low P-chitosan samples should be chosen rather than the P-chitosan samples. High P-chitosan samples may have special use in high loading bone-defect repair. Similarly, the effects of P-chitin in the tissue responses to two CPCs were investigated using a rabbit model [133].

As indicated by Ripamonti and Duneas [134], an ideal biomaterial for bone tissue engineering should be non-immunogenic, biodegradable, highly effective in osteoinduction with relatively low doses of inducing signals, ready for rapid vascular and mesenchymal cell invasion, carvable, and amenable to contouring for optimal adaptation to the various shapes of bone defects, providing mechanical support when needed. The P-CPCs fulfilled all of those requirements and can be considered promising materials for bone repair. Cell response of rat osteoblasts and fibroblasts to water-soluble P-chitin and P-chitosan on the functions was examined in vitro $[135,136]$. The cell morphology was observed at 1,4 and 7 days respectively together with other biological tests. The results suggested that P-chitin and P-chitosan has no toxicity on both cell lines. The stimulatory effect of P-chitin and P-chitosan may be due to the additional $\mathrm{PO}_{3}{ }^{=}$ groups in molecules and could be promising biomaterials for tissue engineering.

\section{Conclusions}

In this review, we have presented different synthesis methods of P-chitin and chitosan and their general features. Phosphorylation of chitin and chitosan have improved their solubility, antibacterial, chelating and ionic conductive properties. Due to these favorable properties these materials have a wide range of applications in the biometerial field. This review also summarized some of the recent applications of these materials in various fields such as adsorbing metal 
ions, fuel cell, drug delivery, food processing and tissue engineering. Within their more promissory usage, P-chitin and P-chitosans can be processed into porous structures for tissue engineering scaffolding. As a result, these polymers would have potential to be applied in cell transplantation and tissue regeneration methodologies. The high sorption capacities of modified P-chitin and chitosan for metal ions can be of great advantage for the recovery of valuable metals or the treatment of contaminated effluents.

\section{Acknowledgements}

R. Jayakumar acknowledges the Portuguese Foundation for Science and Technology for providing him a Post-Doc scholarship (SFRH/BPD/14670/2003). This work was partially supported by FCT Foundation for Science and Technology, through funds from the POCTI and/or FEDER program. This work was partially supported by the European Union funded STREP Project HIPPOCRATES (NMP3-CT-2003-505758).

\section{References}

[1] Muzzarelli, R. A. A.; (Ed.), Natural Chelating Polymers, Pergamon Press, New York, 1973, P.83.

[2] Zikakis, J. P., (Ed.), Chitin, Chitosan and Related Enzymes, Acadamic Press, Orlando, 1984, P. XVII.

[3] Mass, W. A.; Mass, A.; Tighe, B.; Polym. Int. 1998, 47, 89.

[4] Illum, L.; Pharm. Res. 1998, 15, 1326.

[5] Sashiwa, H.; Saimoto, H.; Shigemasa, Y.; Ogawa, R.; Tokura, S.; Int. J. Biol. Macromol. 1990, 12, 295.

[6] Shigemasa, Y.; Saito, K.; Sashiwa, H.; Saimoto, H. Int. J. Biol. Macromol. 1994, 16, 43.

[7] Prabaharan, M.; Borges, J. P.; Godinho, M. H.; Mano, J. F.; Mater. Sci. Forum, 2006, 514-516, 1010.

[8] Park, J. H.; Kwon, S.; Lee, M.; Chung, H.; Kim, J. H.; Kim, Y. S.; Park, R. W.; Kim, I. S.; Bong Seo, S. B.; Kwon, I. C.; Jeong, S. Y.; Biomaterials, 2006, 27, 119.

[9] Shi, C.; Zhu, Y.; Ran, X.; Wang, M.; Su, Y.; Cheng, T.; J. Sur. Res. 2006, 185.

[10] Prabaharan, M.; Mano, J. F.; Carbohyd. Polym. 2006, 63, 153.

[11] Crini, G.; Bioresource Technology, 2006, 97, 1061.

[12] Ng, L.T.; Swami, S.; Carbohydr. Polym. 2005, 60, 523.

[13] Don, T. M.; King, C. F.; Chiu, W. Y.; Peng, C. A.; Carbohydr. Polym. 2006, 63, 331.

[14] Sabnis, S.; Block, L. H.; Int. J. Biol. Macromol. 2000, 27, 181.

[15] Genta, I.; Coatantini, M.; Asti, A.; Conti, B.; Montanari, L.; Carbohydr. Polym. 1998, 36, 81.

[16] Okamoto, Y.; Kawakami, K.; Miyatake, R.; Morimoto, M.; Shigemasa, Y.; Minami, S.; Carbohydr. Polym. 2002, 49, 249.

[17] Schnurch, A. B.; Int. J. Pharm. 2000, 194, 113.

[18] Prabaharan, M.; Mano, J. F.; Macromol. Biosci. 2005, 5, 965. 
[19] Crompton, K. E.; Prankerd, R. J.; Paganin, D. M.; Scott, T. F.; Horne, M. K.; Finkelstein, D. I.; Gross, K. A.; Forsythe, J. S.; Biophys. Chem. 2005, 117, 47.

[20] Tsigos, I.; Martinou, A.; Kafetzopoulos, D.; Bouriotis, V.; Trends in Biotechn. 2000, 18, 305.

[21] Baños, S. B.; Lauzardo, A. N. H.; Velázquez-del Valle, M. G.; HernándezLópez, M.; Barka, E. A.; Bosquez-Molina, E.; Wilson, C. L.; Crop Prod. 2006, 25, 108.

[22] Muzzarelli, R. A. A.; Carbohydr. Polym. 1996, 29, 309.

[23] Ravi Kumar, M. N. V.; React. Func. Polym., 2000, 46, 1-27.

[24] Tokura, S.; Tamura, H.; Biomacromolecules, 2001, 2, 417.

[25] Martino, A. D.; Sittinger, M.; Risbud, M. V.; Biomaterials, 2005, 26, 5983.

[26] Kweon, D. K.; Song, S. B.; Park, Y. Y.; Biomaterials, 2003, 24, 1595.

[27] Mi, F. W.; Shyu,S. S.; Lin, Y. M.; Wu, Y. B.; Peng, C. K.; Tsai, Y. H.; Biomaterials, 2003, 24, 5023.

[28] Jayakumar, R.; Reis, R. L.; Mano, J.F.; Mater. Sci. Forum, 2006, 514-516, 1015.

[29] Risbud, M. V.; Haridikar, A. A.; Bhat, S. V.; Bhonde, R. R.; J. Controlled Release, 2000, 68, 23.

[30] Thanou, M.; Verhoef, J. C.; Junginger, H. E.; Adv. Drug Del. Rev., 2001, $52,117$.

[31] Yao, F.; Chen, W.; Wang, H.; Liu, H.; Yao, K.; Sun, P.; Lin, H.; Polymer, 2003, 44, 6435.

[32] Ding, Z.; Chen, J.; Gao, S.; Chang, J.; Zhang, J.; Kang, E. T.; Biomaterials, 2004, 25, 1059.

[33] Kast, E.; Schnurch, A. B.; Biomaterials, 2001, 22, 2345.

[34] Hendrickson, H. S.; Anal. Chem. 1967, 27, 998.

[35] Westerback, S.; Rajan, K. S.; Martell, A. E.; J. Am. Chem. Soc. 1965, 87, 2567.

[36] Schwarzenbach, G.; Ackermann, H.; Ruckstuhl, P.; Helv. Chim. Acta, 1949, 32,1175 .

[37] Suh, J. K. F.; Matthew, H. W. T.; Biomaterials, 2000, 21, 2589.

[38] Verma, A. J.; Deshpande, S. V.; Kennedy, J. K.; Carbohydr. Polym. 2004, $55,77$.

[39] Senel, S.; McClure, S. J.; Adv. Drug Del. Rev. 2004, 56, 1467.

[40] Kurita, K.; Prog.Polym. Sci. 2001, 26, 1921.

[41] Guibal, E.; Sep. Puri. Techn. 2004, 38, 43.

[42] Berger, J.; Reist, M.; Mayer, J. M.; Belt, O.; Gurny, R.; Eur. J. of Pharam. Biopharm. 2004, 57, 35.

[43] Dung, P.; Milas, M.; Rinaudo, M.; Desbrieres, J. Carbohydr. Polym. 1994, 24, 209.

[44] Kubota, N.; Tatsumoto, N.; Sano, T.; Toya, K.; Carbohydr. Res., 2000, 324, 268.

[45] Muzzarelli, R. A. A.; Carbohydr. Polym. 1988, 8, 1.

[46] Muzzarelli, R. A. A.; Ilari, P.; Petrarulo, M.; Int. J. Biol. Macromol. 1994, 16, 177.

[47] Muzzarelli, R. A. A.; Ilari, P.; Tomasetti, M.; Carbohydr. Polym. 1993, 20, 99. 
[48] Hamodrakes, S. J.; Jones, C. W.; Kafatos, F. C.; Biochim. Biophys. Acta, 1982, 700, 42.

[49] Hampdrakes, S. J.; Asher, S. A.; Mazur, G. D.; Regier, J. C.; Kafatos, K. C.; Biochim. Biophys. Acta, 1982, 703, 216.

[50] Sakaguchi, T.; Hirokoshi, T.; Nakajima, A.; Agric. Biol. Chem. 1981, 45, 2191. [51] Nishi, N.; Nishimura, S.; Ebina, A.; Tsutsumi, A.; Tokura, S.; Int. J. Biol. Macromol. 1984, 6, 53.

[52] Nishi, N.; Ebina, A.; Nishimura, S.; Tsutsumi, A.; Hasegawa, O.; Tokura, S.; Int. J. Biol. Macromol. 1986, 8, 311.

[53] Somorin, O.; Nishi, N.; Tokura, S.; Naguchi, J.; Polym. J., 1979, 11, 391-395.

[54] Kaifu, K.; Nishi, N.; Komai, T.; Tokura, S.; Somorin, O.; Polym. J. 1981, 13, 241.

[55] Nishi, N.; Ohnuma, H.; Nishimura, S.; Somorin, O.; Tokura, S.; Polym. J. 1982, 14, 919.

[56] Nishi, N.; Noguchi, J.; Tokura, S.; Noguchi, J.; Polym. J. 1979, 11, 27.

[57] Nishi, N.; Maekita, Y.; Nishimura, S.; Hasegawa, O.; Tokura, S.; Int. J. Biol. Macromol. 1987, 9, 109.

[58] Yalpani, M. Carbohydr. Polym. 1992, 19, 35.

[59] Jung, B. O.; Kim, C. H.; Choi, K. S.; Lee, Y. M.; Kim, J. J.; J. Appl. Polym. Sci. 1999, 72, 1713.

[60] Heras, A.; Rodriguez, N. M.; Ramos, V. M.; Agullo, E.; Carbohydr. Polym. 2001, 44, 1.

[61] Moedritzer, K.; Irani, M.; J. Org. Chem. 1966, 31, 1603.

[62] Ramos, V. M.; Rodriguez, N. M.; Diaz, M. F.; Rodriguez, M. S.; Heras, A.; Agullo, E.; Carbohydr. Polym. 2003, 52, 39.

[63] Yoshioka, H.; Nonaka, K.; Fukuda, K.; Kazama, S.; Biosci. Biotech. \& Biochem., 1995, 59, 1901.

[64] Miwa, A.; Ishibe, A.; Nakano, M.; Yamahira, T.; Itai, S.; Jinho, S.; Kawahara, H.; Pharam. Res. 1998, 15, 1844.

[65] Sluddin, J.; Uchegebu, I. F.; Schatzlein, A. G.; J. Pharam. Pharmcol. 2000, $52,377$.

[66] Ramos, N. M.; Rodriguez, N. M.; Rodriguez, M. S.; Heras, A.; Agullo, E.; Carbohydr. Polym. 2003, 51, 425.

[67] Lebouc, F.; Dez, I.; Madec, P. J.; Polymer, 2005, 46, 319.

[68] Lukasiewicz, A.; Tetrahedron, 1963, 19, 1789.

[69] Pine, S. H.; Sanchez, B. L.; J. Org. Chem. 1971, 36, 829.

[70] Agullo, E.; Ramos, V.; Rodriguez, N.; Heras, A.; AR Patent, 2000, 000101260.

[71] Muzzarelli, R. A. A.; Zattoni, A. Z.; Int. J. Biol. Macromol. 1986, 8, 137.

[72] Muzzarelli, R. A. A.; Ramos, V.; Stanic, V.; Dubini, B.; Mattioli, M.; Tosi, G.; Giardino, R.; Carbohydr. Polym. 1986, 36, 267.

[73] Ramos, V. M.; Rodriguez, M. S.; Agullo, E.; Int. J. Polym. Mat. 2002, 51, 711. [74] Jayakumar, R.; Reis, R. L.; Mano, J. F.; J. Bioact. Compat. Polym. 2006 (In press).

[77] Uragami, T.; Yoshida, F.; Sugihara, M.; Macromol. Chem. Rapid. Commun.,1983, 4, 99. 
[78] Yamada, M.; Honma, I.; Angew. Chem. Int. Ed., 2004, 43, 3688.

[79] Prabaharan, M.; Mano, J, F.; Drug Delivery, 2005, 12, 41.

[80] Jayakumar, R.; Reis, R. L.; Mano, J. F.; Drug Delivery, 2006 (in press).

[81] Ghanem, A.; Skonberg, D.; J. Controlled Release, 2001, 71, 127.

[82] Foger, F.; Schmitz, T.; Schnurch, A.B.; Biomaterials, 2006, 27, 4250.

[83] Mi, F. L.; Sung, H. W.; Shyu, S. S.; Carbohydr. Polym. 2002, 48, 61.

[84] Shu, X. Z.; Zhu, K. J. Int. J. Pharm. 2000, 201, 51.

[85] Win, P. P.; Ya, Y. S.; Hong, K. J.; Kajiuchi, T.; Carbohydr. Polym., 2003, 53, 305.

[86] Hadgraft, J.; Valenta, C.; Int. J. Pharm. 2000, 200, 243.

[87] Sorlier, P.; Denuziere, A.; Viton, C.; Domard, A.; Biomacromolecules, 2001, $2,765$.

[88] Win, P. P.; Ya, Y. S.; Hong, K. J.; Kajiuchi, T.; Polym. Int. 2005, 54, 533.

[89] Tuzlakoglu, K.; Alves, C. M.; Mano, J. F.; Reis, R. L.; Macromol. Biosci. 2004, 4, 811.

[90] Jayakumar, R.; Prabaharan, M.; Reis, R. L.; Mano, J. F.; Carbohydr. Polym. 2005, 62, 142.

[91] Hench, L. L.; Wilson, J.; An Introduction to Bioceramics, Advanced Series in Ceramics, Singapore: World Scientific, 1993, 1, 365.

[92] Abe, Y.; Kokubo, T.; Yamamura, T.; J. Mater. Sci. Mater. Med. 1990, 1, 233.

[93] Dalas, E.; Kallitis, J. K.; Koutsoukos, P. G.; Langmuir, 1991, 7, 1822.

[94] Tretinnikov, O. N.; Kato, K.; Ikada, Y.; J. Biomed. Mater. Res. 1994, 28,1365.

[95] Hato, K.; Kokubo, T.; Nakumura, T.; Yamamura, T.; J. Am. Ceram. Soc. 1995, 78, 1049.

[96] Mucalo, M. R.; Yokogawa, Y.; Toriyama, M.; Suzuki, T.; Kawamoto, Y.; Nagata, F.; Nishizawa, K.; J. Mater. Sci. Mater. Med. 1995, 6, 597.

[97] Yokogawa, Y.; PazReys, J.; Mucalo, J.; Toriyama, T.; Kawamoto, Y.; Suzuki, T.; Nishizawa, K.; Nagata, F.; Kameyama, T.; J. Mater. Sci. Mater. Med. 1997, 8, 407.

[98] Mucalo, M. R.; Yokogawa, Y.; Toriyama, M.; Suzuki, T.; Kawamoto, Y.; Nagata, F.; Nishizawa, K.; J. Mater. Sci. Mater. Med. 1995, 6, 409.

[99] Varma, H. K.; Yokogawa, Y.; Espinosa, F.; Kawamoto, Y.; Nishizawa, K.; Nagata, F.; Kameyama, T.; Biomaterials, 1999, 20, 879.

[100] Aoki, H.; In Medical Applications of Hydroxyapatite, Ishiyaku Euro America Inc. Tokyo, St. Louis, 1994, 156.

[101] Okada, K.; Yokogawa, Y., Kameyama, T.; Kato, K.; Kawamoto, Y.; Nishizawa, K.; Nagata, F.; Okuyama, M.; Bioceramics, 1997, 10, 329.

[102] Yokogawa, Y.; Nishizawa, K.; Nagata, F.; Kameyama, T.; J. Sol-Gel Sci. Techn. 2001, 21, 105.

[103] Kokubo, T.; Glass Ceramic: Processing and Properties. In. Hench, L. L.; Wilson. J.; (Eds.). An Introduction to Bioceramics. Singapore: World Scientific, 1993, 81.

[104] Tretinnikov, O. N.; Kato, K.; Ikada, Y.; J. Biomed. Mater. Res. 1994, 28, 1365.

[105] Blumenthal, N. C.; Clin. Orthop. Relat. Res. 1987, 247, 279.

[106] Smetana, K.; Stol, M.; Novak, M.; Danes, J.; Biomaterials, 1996, 17, 1563. 
[107] Glimcher, M. J.; Anal. Rec. 1989, 224, 139.

[108] Li, S. T.; Katz, E. P. Calcif. Tissue. Res. 1977, 22, 275.

[109] Termine, J. D.; Kleinman, H. K.; Whitson, S. W.; Conn, K. M.; McGarvey, M. L.; Martin, G. R.; Cell, 1981, 26, 99.

[110] Lee, S. L.; Veis, A.; Glonek, T. Biochemistry, 1977, 16, 2971-2979.

[111] Boskey, A. L.; Clin. Orthop. Relat. Res. 1992, 261, 244.

[112] Andrew, C. A. W.; Khor, E.; Hastins, G. W.; Biomaterials, 1998, 19, 1309.

[113] Aoba, T.; Moreno, E. C.; J. Colloid. Interface. Sci. 1985, 106, 110.

[114] Boskey, A. L.; Dick, B. L.; Calcif. Tissue. Res. 1991, 49, 193.

[115] Yin, Y. J.; Luo, X. Y.; Cui, J. F.; Wang, C. Y.; Guo, X. M.; Yao, K. D.; Macromol. Biosci. 2004, 4, 971.

[116] Amaral, I. F.; Granja, P. L.; Barbosa, M. A.; Key Eng. Mater. 2004, 254.

[117] Damien, J. C.; Parson, J. R.; J. Appl. Biomater. 1991, 2, 187.

[118] Binderman, I.; Fin. N.; Bone substitutes-organic, inorganic and polymeric.

Cell material interactions. In: Yamamuro, I.; Hench, L.; Wilson J.; (Eds.). CPC Handbook of Bioactive Ceramics. Boca Raton, F. L.: CPC Press, 1990, 45-51.

[119] Langstaff, S.; Sayer, M.; Smith, T. J. N.; Pugh, S. M.; Biomaterials, 2001, 22, 135.

[120] Costantino, P. D.; Friedman, C. D.; Lane, A. Facial. Plast. Surg. 1993, 9, 1.

[121] Kobayashi, S.; Hara, H.; Okudera, H.; Takemac, T.; Sugita, K.; Neurosurgery, 1987, 21, 751.

[122] Wolfe, S. A. Plast. Reconstr. Surg. 1993, 68, 429.

[123] Munting, E.; Mirtchi, A. A.; Lemaitrc, J.; J. Mater. Sci.Meter. Med. 1993, 4, 337.

[124] Kent, J. N.; Quinn, J. H.; Zide, M. F.; Guerra, L. R.; Boyne, P. J.; J. Oral. Maxillofac. Surg. 1987, 41, 629.

[125] Yoshimine, Y.; Sumi, M.; Isobe, R.; Anan, H.; Maeda, K.; Biomaterials, 1996, 23, 2241.

[126] Patrick, F.; Laurent, G.; Philippe, C.; Jacques, F.; Nicole, R.; Biomaterials, 1998, 19, 971.

[127] Ishikawa, K.; Miyamoto, Y.; Kon, M.; Nagayama, M.; Asaoka, K.; Biomaterials, 1995, 16, 527.

[128] Cherng, A.; Takagi, S.; Chow, L. C.; J. Biomed. Mater. Res. 1997, 35, 273.

[129] Boudeville, P.; Serraj, S.; Leloup, J. M.; Margerit, J.; Pauvert, B.; Terol, A.; J. Mater. Sci.: Mater. Med. 1999, 10, 99.

[130] Takagi, S.; Chow, L. C.; Ishikawa, K.; Biomaterials, 1998, 19, 1593.

[131] Wang, X.; Ma, J.; Wang, Y.; He, B.; Biomaterials, 2001, 22, 2247.

[132] Wang, X.; Ma, J.; Wang, Y.; He, B.; Biomaterials, 2002, 23, 4167.

[133] Wang, X.; Ma, J.; Feng, Q.; Cui, F.; Biomaterials, 2002, 23, 4591.

[134] Ripamonti, U.; Duneas, N.; MRS Bull. 1996, 21, 36.

[135] Wang, X. H.; Zhu, Y.; Feng, Q. L.; Cui, F. Z.; J. Bioact. Compat. Polym. 2003, 18, 135.

[136] Zhu, Y.; Wang, X. H.; Cui, F. Z.; J. Bioact. Compat. Polym. 2003, 18, 375. 